\title{
LAPAROSCOPIC CHOLECYSTECTOMY : \\ A NEW ERA IN THE FIELD OF SURGERY \\ IN BANGLADESH
}

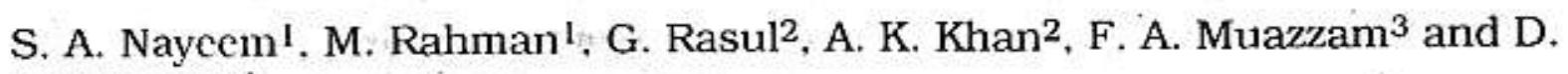
Hashimoto ${ }^{4}$

\section{Summary}

Laparoscopic cholecystectomy which is the latest development in the field of general surgery has recently been introduced in Bangladesh. We performed this less Invasive surgery successfully on two cases of cholelithiasis for the lirst time in Bangladesh, one in BIRDEM Hospital and another in IPGMR Hospital in December, 1991. Though for those demonstrative cases. the set-up was diflicult in a new place but there was no mojor technical problem during the procedure. After that there was a fong gap and our team has started this procedure from April, 1993 regularly at two hospitals in Dhaka. By September, 1993 we have already performed over 100 cases of laparoscopic cholecystectomy successfully. This paper will describe the patient selection. preoperalive investigation, operative procedure and postoperative care of laparoscopic cholecyste ctomy. the newest treatment modality for gallbladder diseases.

Key Words : Laparoscopic cholecystectony. laparoscopy with abdominal wall Jifting. Cholelithiasis, Cholecystitis

\section{Introduction}

Causing less tramma and least pain to the patient are the prime considerations for any modern surgical procedure. In the development of surgery. surgeons and researchers have always put in ardent ellorts 10 introduce least invasive ways of treatment with the best results. Laparoscopic cholecystectomy is one of those efforts which is considered as a revolutionary cuent in the field of surgery. This latest treatment modality for the management of gallbladder diseases has already been proved to be promising and gained a wide range of acceptibility. Though the standard open cholecystectomy is established as

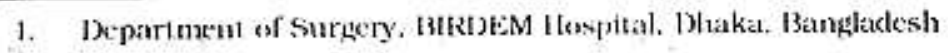

2. Department of Surgery. If'GMR. Dhakis, Banglade'ste

3. Departmen of Suriery. Cancet Rescureh lnstilute. Dhaka. Banglelesh

4. 1)epartment of Surdery. Tokyo Metreposlitan Police: llisspitat. Tokyo: 
a highly safe and ellective means of treating gallbladder cliseases, especially cholelithiasis, for decades. the nowel procedure has shown superiority regarding safety, ellicacy and morbidity. laparoscopic: cholecystcctomy is the milcstone, which opened a new era in the fleld of general surgery. In $1987 \mathrm{P}$. Muret ${ }^{1}$ and his colleagues in France perlonned the first complete removal of a diseased gallbladier in a patient by laparoscopic procedure. The procedure has rapidly evolved as the most appropriate therapeutic modality for the treatment of gallbladder diseases in the developed countries throughout the world. Bangladesh has also seen the introduction of this hishly sophislicated procedure which is a landmark in her medical history. The lirst two demonstrative cases of laparoscopic cholecystectomies wre performed at the end of 1991 by our group in Dhaka. From Aprll of 1993 we have slarted this procedure regularly at two hospitals in Dhaka. Bangladesh. We have applied pnetmoperitoneum and abdominal wall lifting by subculaneous wiring for making the operative space inside the abdomen. There was no case selection for the methods: we randonly performed laparoscopic cholecysiectomy will preumoperitoneum in onc hospital and with abdominal wall lifting wilhout pneumoperitoneum in another. There was no significant dillerence in average operative time and. the quality of operative view was almost the same. However, the risks of complications of pneumoperitoneum were completely eliminated by the newer procedure of abdominal wall lilting. The running cost of the operation was also signilicantly reduced by the lilting method. Or the reported complications of lajparoscopic cholecystectomy we have encountered none in our series.

\section{Patient Selection, Preoperative Investigation, Operative Procedure}

Though the indications for laparoscopic cholecystectomy are essentially the same as open cholecystectomy. we avoided the patients with active inflammation and common bileduct (CBD) stones. An ullrasonography and an oral cholecystography or intravenous drip Infusion cholangiography are recommended for preoperative evaluation. Suspected common bile duct stone can be craluated by ERCP* and managed by removal of stone with endtascopic papillotomy 2,3.4.

Since the procedure is a unique combination of modern video and camera technology with sophisiticated surgical techniques. a lull set up with camera, video system and monitors is essential to go for this surgery (Fig. 1). Also a lull set of specially designed equipments for this procedure is necessary with speciall sterilization techniques.

General anesthesia is administered via cndotracheat intubation. Adequate muscle relaxant is administered to facilitate the abdominal wall lliting or pneumoperitoneum. which is considered as the very lirst step of any laparoscopic procedure. Abdominal wall lifting or pneumoperitonem is performed to make the adequate space instde the abclomen to pertonn the surgical mancuvers for cholecystectomy.

Preumoperitoneum is acheived by an automatic machine which provides us the space in the abdomen 10 pertonn the procedure by peritoneal insulilation by $\mathrm{CO}_{2}$ gas into the

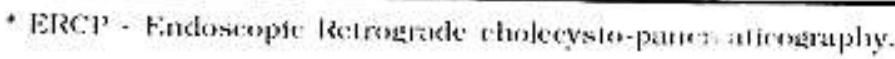




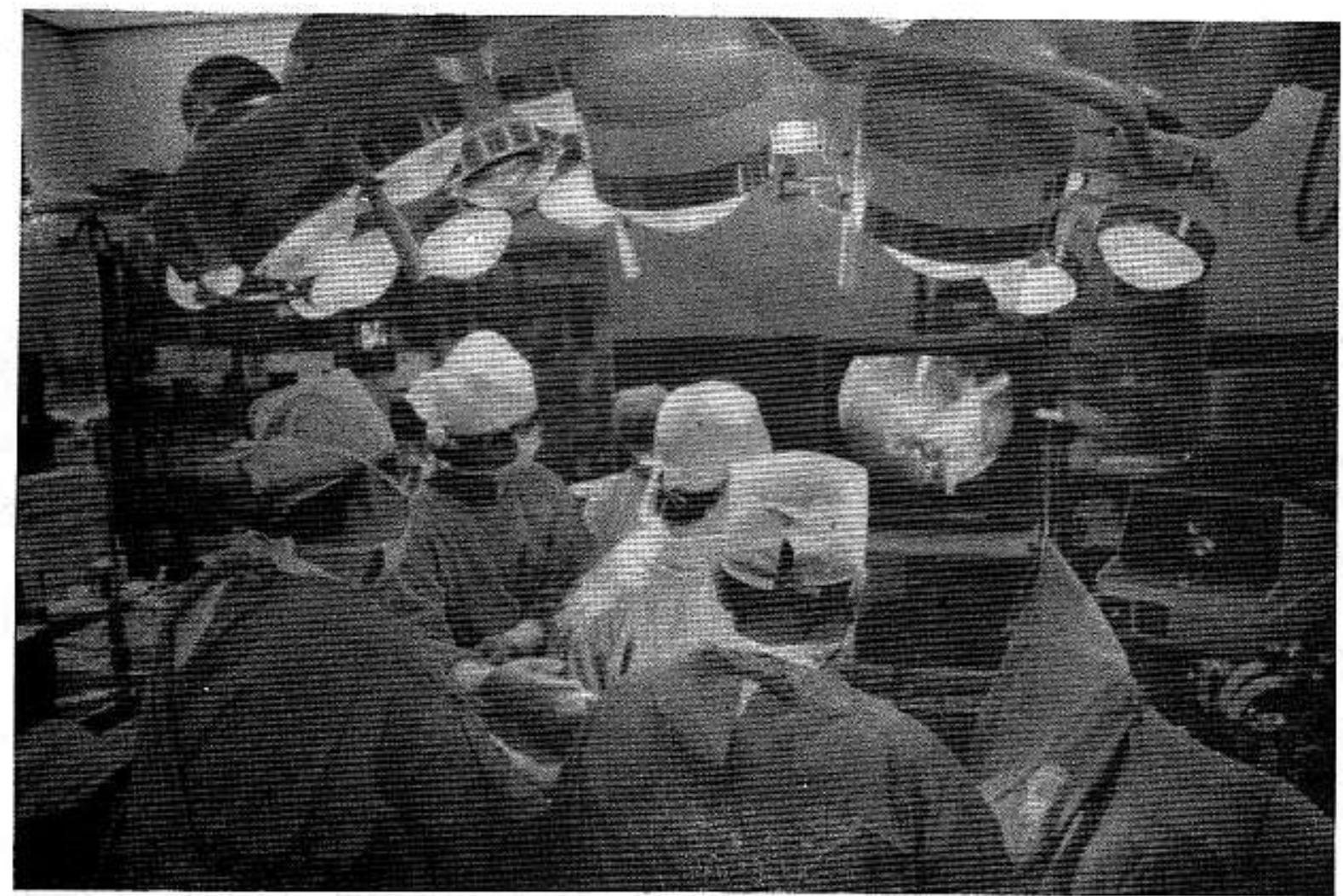

Fig. 1: Operation room set up; the monitor is placed in front of the surgeon and the assistants.

peritoneal cavity. The intribabdominal pressure is autonatis ally regulated for maintaining a constant pressure during pneumoperitoneum. A high flow insufflating capacity is atso required for a quicker attainment of pneumoperitoneum. In a supine position after the induction of general anesthesia, painting and drapping. the patient is brought into Trendelenburg's position and a veress needle is introduced through a small incision just below the umbilicus. Then pneumoperitoneum is created by insuflating $\mathrm{CO}_{2}$ gas and an - intra-abdominal pressure of $12 \mathrm{~mm}$ of $\mathrm{Hg}$ is achieved.

We ${ }^{5,6}$ devised an alternative method to make the same room by lifting up the abdominal wall, by the help of subcutaneous wires and thick sutures. Two $30 \mathrm{~cm}$ long and $2-3 \mathrm{~mm}$ diameter strong stainless stecl wires were passed under the skin, one parallel to the right costal margin and another transversely above or below the umbilicus. Then lifting of the anterior abdominal wall was done by anterior. upward and little outward traction of these rods using No.-5 Ethibond suture and the traction was maintained by the help of hooks, an arch and clamp bars used in Kent extension retractor set for open abdominal surgery (Fig. 2), A fairly good room is produced intraabdominally which was enough for performing the cholecystectomy procedure.

The operation is performed through four small punctures (Fig. 3). A $10 \mathrm{~mm}$ trocar is introduced through the umbilicus through which the telescope is inserted and the intra- 


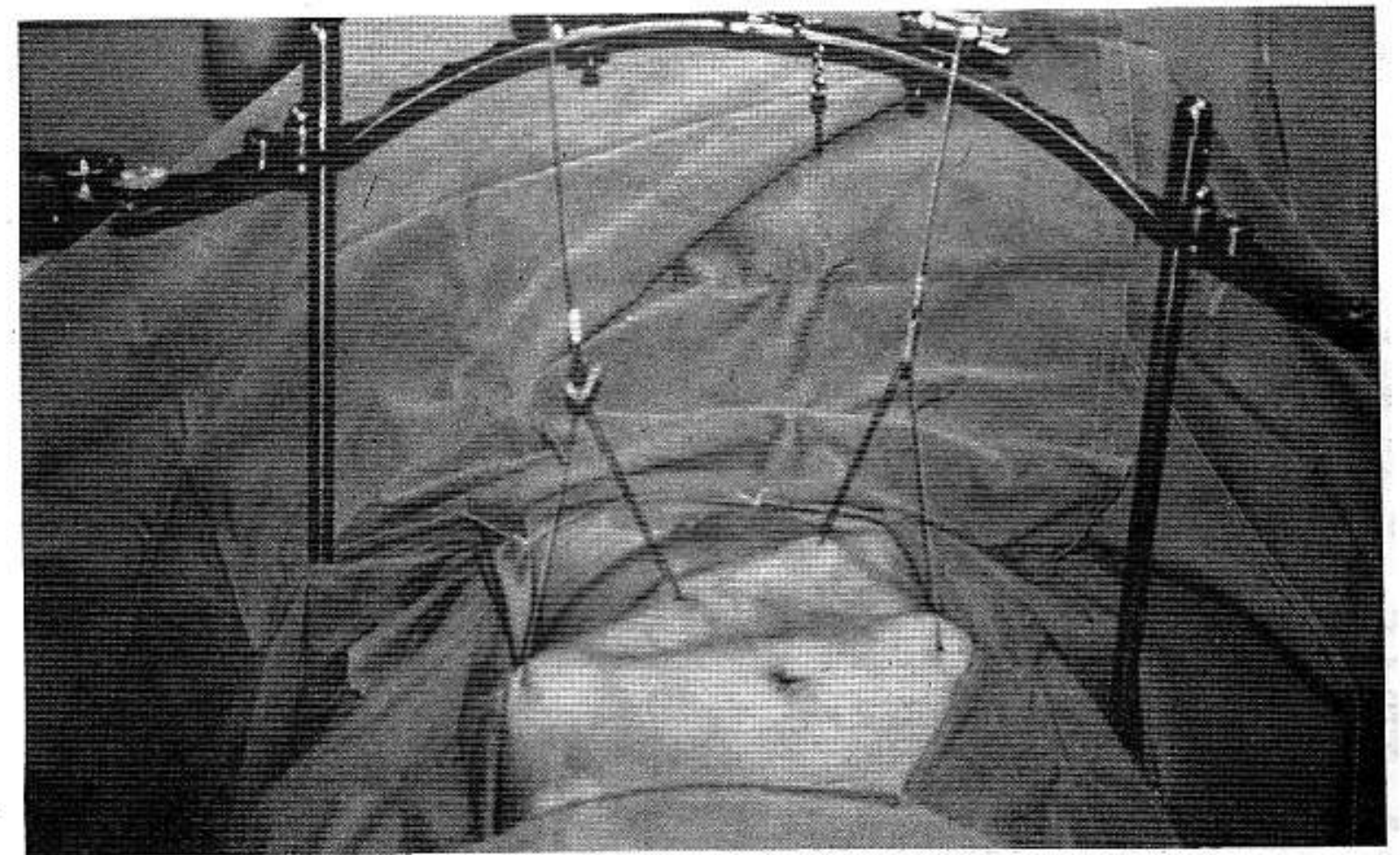

Fis, 2. Abdoninal wall lifting for creatling the spars: inside the abdomen

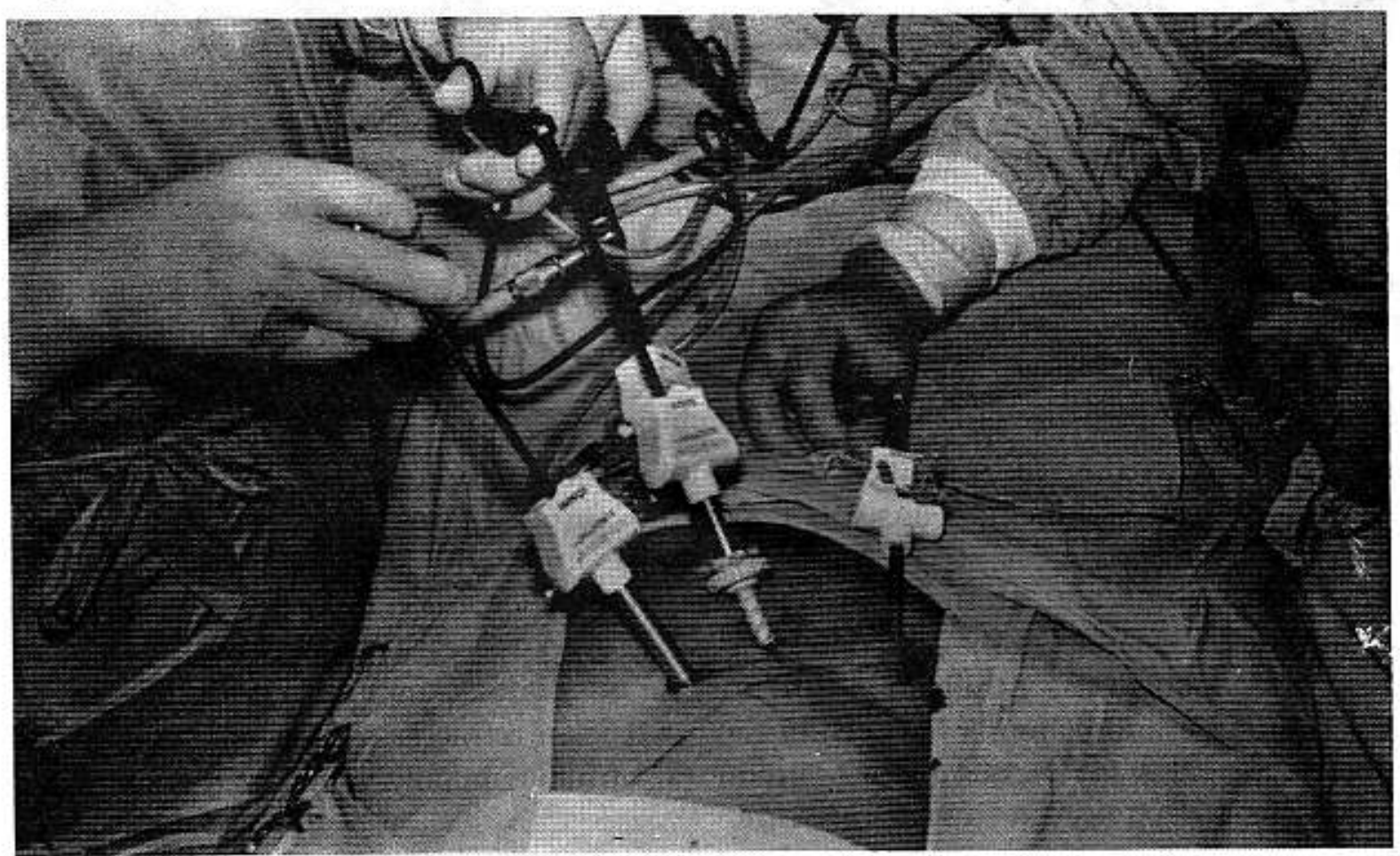

Fis. 3: Four trocars in Ile dxclominal wall, allowing the entry into the abclomen for operative maneuvers 
abdominal view is found in the monitors (Fig. 4). After a circular inspection of the intraabdominal structures and the gallbladder, other three trocar are inserted under direct observation in the monitors. Two $5 \mathrm{~mm}$ trocars are inserted in the midclavicular line two linger widths beneath the right costal margin and in the anterior axillary line three finger widths beneath the right costal margin. The second $10 \mathrm{~mm}$ trocar is inserted in $1 / 3$ rd distance between the xiphoid and the umbilicus just to the right of the midline.

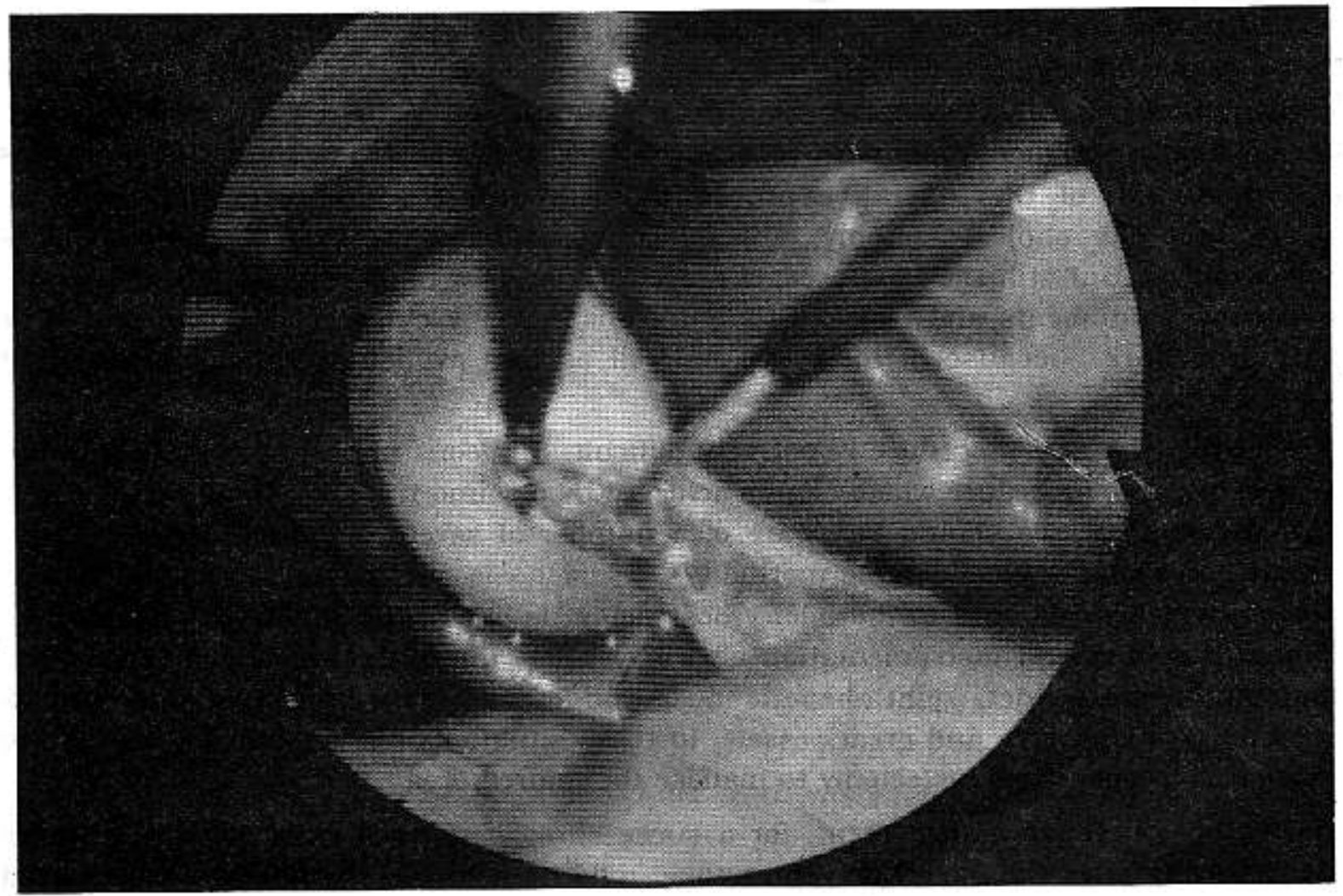

Fig. 4: Laparoscopic: view of the neck of the gallbladder in the monitor.

Keeping the fiberscope in the umbilical trocar and lifting and pusting the gallbladder fundus by an atraumatic lorceps through the lateral (anterior axillary) portal, dissection and cleaning of the cystic duct and artery is performed using some especially designed instruments through the other two trocars. The next step is clipping the artery and duct and resection in between the clips. After resection of the duct and artery the gallbladder is freed from its liver bed in a retrograde manner either using simple electrocautery or blunt dosscetion. At the linal stage the gallbladder was removed by the jaws forceps through the umbilical trocar under monitoring from inside through the midline trocar.

After confirming a complete hemostasis, small incisions are closed using one or two sutures in the peritoneum and muscle without any skin suture ${ }^{7.8}$. 


\section{Discussion}

Laparoscopic cholecystectony is probably the best suited procedure among all endoscopic operations to receive a world wide acceptance. Though the procedure is very new and time has not come to comment on the safety. effectivity and also on the long term postoperative course of the procedure. It has gained a very high rate of popularity among surgeons and patients ${ }^{9,10}$.

Excellent quality video camera, monitoring and high volume insulflator are among the most important equipments which made laparoscopic sugical procedures posstble to perform successfully. Instead of a direct visualization with a long incision. two dimensional video monitoring of the operative field with a less invasive portal of entry is the main aim of this operative procedure and became widely preferred in some operations like cholecystectomy, appendectomy, adhesiolysis etc. because of less invasiveness. But still the laparoscopic procedure needs a number of sophisticated and expensive equipments and restricts the surgeons of many clinics to start and perform this procedure because of high cost as well as less availability of many essential equipments.

Technically the new procedure is not very difficult. Surgeons need an orientation before performing this procedure which can be achieved by a sound training. Though it is a less Invasive surgery. we should be aware of a number of severe operative complications. These can cause a considerable morbidity. Misdiagnosis of the anatomy of the biliary system which might lead to the billary obstruction is one of the serious complications. Trocar insertion and instrumentation also may cause injury to the common bile duct. common hepatic ddct, right. hepatic duct and other organs like liver, intestine \& mesentery, diaphragm and great vessels. In these situations one should not hesitate to convert it to open cholecystectomy to manage the injured organ.

As for postoperative management, for a successfully performed case, patient recovers dramatically after the operation. Some time, mild pain in the wounds are experienced which even does not require any analgesic. In pneumoperitoneum cases, mild shoulder pain can be experienced due to stressing of the diaphragm, which recovers with mild dose of analgesic.

In conclusion this new treatment procedure for gallbladder disease will certainly take its place as the treatment of choice in the near future. It will in course reduce the morbidity. hospital cost as well as overloading pressure on the surgical departments in a country like Bangladesh.

\section{References}

1. Philipe Mouret el al, Laparoscopic cholecystectomy in human. Personal communication. France, 1987

2. Fitzgibbons RJ Jr, Schmid S, Santoscoy R. Hinder R. Filipl CJ et al, Laparoscopic cholecystectomy: The beginning of a new era in general surgery (submitted for publication). 
3. Filipi CJ.. Fitzgibbons RJ. Salerno, GM, Historical Review : Diagnositc laparoscopy to laparoscopic cholecyslectomy and beyond. Surgical Laparoscopy. Zucker KA (ed). pp. 3-21 1991.

1. Dubois F. Icard P, Berthelot G, Levard H. Coelioscopic Cholecystectomy. Ann Surg $1: 60$ 62. 1990.

5. Hashimoto D. Nayeem SA. Kajiwara S. Hoshino T. Laparoscopic Cholecystectomy. An approach without pneumoperitoneum. Surg Endose $7: 54-56,1993$.

6. Hashimolo D. Nàyeem SA. Kajjiwara S. Hoshino T. Laparoscopic Cholecyatectomy : A New Approach Without Pneumoperitoneum. (Abstract) SAGES I'rogram, p 591992.

7. Reddick EJ. Olsen DO. Laparoscopic laser cholecystectomy. Surg Endosc 3: 131-33, 1989.

* Reddick EJ. Olsen DO. Outpatlent laparoscopic laser cholecystectomy. Am J Surg 160:8589. 1990.

9. Zucker KA, Bailey RB, Gadacz TR, Imbembo AL. Laparoscopic guided cholecystectomy. Am J Surge $161: 36.44 .1891$.

10. Philips E, Daykhovsky L. Carrol B. el al. laparoscopic Cholecystectomy : Instrumentation and Technique. J Laparostopic Surg 1 (1) ; 3-15. 1990.

\section{The Hippocralic Oath}

I swear that I will follow that system of regimen which according to my ability and judgment. I consider for the benefit of my patients, and abstain from whatever is deleterious and mischievous. I will give no deadly medicine to any one if asked, nor suggest any such counsel: and in like manner I will nol give to a woman a pessary to produce abortion. With purity and holiness I will pass my life and practise my art. I will not cut persons labouring under the stone but will leave this to be done by men who are practitioners of this work. Into whatever houses I enter, I will go into them for the benefil of the sick, and will absiain from every voluntary act of mischeif and corruption. Whatever. in connection with my professional practice, or not in connection with it, I see or hear, in the life of men, which ought not to be spoken of abroad. I will not divulge, as reckoning that all such should be kept secret. While I continue to keep this Oath unviolated. may it be granted to me to enjoy life and the practice of the art, respected by all men, in all times: but shbuld I trespass and violate this Oath, may the reverse be my lot. 